\title{
Stability and Dynamics in an Overlapping Generations Economy under Flexible Wage Negotiation and Capital Accumulation
}

\author{
Erkki Koskela \\ University of Helsinki, RUESG and HECER \\ and \\ Mikko Puhakka \\ University of Oulu
}

Discussion Paper No. 127

October 2006

ISSN 1795-0562

HECER - Helsinki Center of Economic Research, P.O. Box 17 (Arkadiankatu 7), FI-00014 University of Helsinki, FINLAND, Tel +358-9-191-28780, Fax +358-9-191-28781, E-mail info-hecer@helsinki.fi, Internet www.hecer.fi 


\title{
Stability and Dynamics in an Overlapping Generations Economy under Flexible Wage Negotiation and Capital Accumulation*
}

\begin{abstract}
We analyze the stability and dynamics of an overlapping generations model under imperfectly competitive labour markets without population growth and with perfect foresight. Under right-to-manage wage bargaining we assume that wage is negotiated after the decision on the capital stock. With Cobb-Douglas utility and production functions the steady state is unique and the steady state capital stock depends positively on the trade union's bargaining power. This is because higher bargaining power of the trade union will induce workers to save more thus boosting the capital stock, ceteris paribus. Finally, we show that the steady state equilibrium is a saddle point.
\end{abstract}

JEL Classification: J51, C62.

Keywords: Overlapping generations economy, capital accumulation, flexible wage negotiation, stability and dynamics.

Erkki Koskela

Department of Economics

University of Helsinki

P.O. Box 17 (Arkadiankatu 7)

FI-00014

FINLAND

e-mail: erkki.koskela@helsinki.fi
Mikko Puhakka

Department of Economics

University of Oulu

P.O. Box 4600

FI-90014

FINLAND

e-mail: mikko.puhakka@oulu.fi

* The authors thank the Research Unit of Economic Structures and Growth (RUESG) at the University of Helsinki and the Yrjö Jahnsson Foundation for financial support. Koskela also thanks Academy of Finland (grant No. 1109089) for financial support as well as CES at the University of Munich both for financial support and its nice hospitality. 


\section{Introduction}

It has been suggested that trade unions may affect the level of capital stock through their impact on wages and employment. Originally, Grout (1984) argued that in a situation where firms and trade unions bargain over both the wage and employment, the unions will have a negative effect on the level of investment in the absence of committed wage negotiation. Moreover, he argued that without binding contracts a higher bargaining power of the trade union will always lower the capital stock. van der Ploeg (1987) demonstrated the similar result in the right-to-manage case where the wage is subject to bargaining under the condition that labour demand is determined by firms. Anderson and Devereux (1988) suggested that the presence of monopoly trade union might lead to more serious adverse welfare effects than in the frameworks, which abstract from the strategic effect of the firm's investment decision, i.e. when the firm can commit itself to a capital stock decision before wage determination. Anderson and Devereux (1991) used a monopoly trade union model to study the trade-off between the benefits of wage commitment and the costs of wage inflexibility in the design of the optimal contract length. They argue that there is a natural welfare trade-off between wage commitment and wage flexibility.

Devereux and Lockwood (1991) used a simple overlapping generations (OG) model with capital (Diamond 1965) and unions to provide a counterexample to some findings of Grout (1984) and van der Ploeg (1987). They argued that a move from a committed to a flexible wage negotiation, i.e. when wages are negotiated not before but after the capital stock decision, may increase the capital stock as a result of the rise in the trade union's bargaining power. This occurs in their model because higher bargaining power of trade union increases wage income and thus savings of the young generation.

de la Croix and Licandro (1995) utilized a slightly different version of an OG model with capital and unions to investigate the effects of different types of irreversibilities on economic growth. Among other things they showed that a rise in trade union power may induce a crowding-out of physical capital by pure profits so that the effect on capital stock in their model is ambiguous.

Dos Santos Ferreira and Lloyd-Braga (2002) and Bertocchi (2003) have recognized the importance of trade unions for economic growth. They have utilized the overlapping generations model with trade unions to study certain issues of 
economic growth. Dos Santos Ferreira and Lloyd-Braga have shown that endogenous growth is possible in a rather simple OG model with imperfect competition including wage bargaining. Bertocchi on the other hand has argued that e.g. the convergence of incomes between countries depends heavily on the structure of their labour markets. Both of these papers, however, and unlike we, utilize efficient wage bargaining.

It is important to point out that in most of these papers the emphasis was not in the precise analysis of stability and dynamics. We focus on these issues by extending the model of Devereux and Lockwood (1991). We use the right-tomanage wage bargaining and derive labour demand given the negotiated wage and capital stock decided by firms. We modify a closed economy OG framework by incorporating imperfectly competitive labour markets via Nash wage bargaining. Under right-to manage wage bargaining, where employment is not negotiated but decided by firms, we assume that wage is negotiated given the capital stock. Wage bargaining takes place between the young workers and the old capitalists.

We demonstrate the following results. With Cobb-Douglas utility and production functions the economy's steady state is unique under imperfectly competitive labour market, and the steady state capital stock depends positively on the trade union's bargaining power. This happens because higher bargaining power of the trade union will induce workers to save more, which boosts the capital stock. Finally, we study the dynamics of the model and show that the steady state equilibrium is a saddle point.

We proceed as follows. In section 2 we present the basic framework and comparative statics of an overlapping generations model under Nash wage bargaining, where wages are negotiated after the capital stock has been decided by the representative firm. Section 3 analyses the steady state equilibrium and dynamics under flexible wage negotiation. Finally, there is a concluding section where we briefly summarize our new findings.

\section{An Overlapping Generations Model under Wage Bargaining}

We study an overlapping generations model without population growth (the amount of population is normalized to be unity) and with perfect foresight. The young in each period are endowed with one unit of time, which they inelastically 
supply to the market. Their retirement consumption is provided by their savings, which can be invested in two assets. They supply capital to the firms, and also buy shares of those firms. There is an operative stock market here, because there will be profits due to the existence of trade unions and decreasing returns to scale. These are due either to technology, one fixed input or imperfectly competitive product markets. Later on we describe these three possibilities more precisely.

We incorporate imperfect competition in labour markets into an overlapping generations model. The young workers form a labor union. They negotiate about the wage with the firm's owners. There is right-to-manage (RTM), and thus employment is determined by firms (for alternative formulations of trade union models, see e.g. Cahuc and Zylberberg (2004), chapter 7).

As in Devereux and Lockwood (1991) we assume that the worker-consumers have the following Cobb-Douglas utility function

$$
u\left(c_{1}^{t, i}, c_{2}^{t, i}\right)=\left(c_{1}^{t, i}\right)^{\lambda}\left(c_{2}^{t, i}\right)^{1-\lambda}, 0<\lambda<1,
$$

where $c_{j}^{t, i}$ refers to the consumption of the person born at the beginning of period $t$ in the $j^{t h}$ period of his life $(j=1,2)$ if he is either employed $(i=E)$ or unemployed $(i=U)$. The young of each generation are endowed with a unit of labour which they supply inelastically. The periodic budget constraints of the employed person are

$$
\begin{aligned}
& c_{1}^{t, E}+k_{t+1}^{E}+q_{t} \theta_{t+1}^{E}=w_{t} \\
& c_{2}^{t, E}=R_{t+1} k_{t+1}^{E}+\left(d_{t+1}+q_{t+1}\right) \theta_{t+1}^{E} .
\end{aligned}
$$

The unemployed person's constraints are respectively

$$
\begin{aligned}
& c_{1}^{t, U}+k_{t+1}^{U}+q_{t} \theta_{t+1}^{U}=b_{t} \\
& c_{2}^{t, U}=R_{t+1} k_{t+1}^{U}+\left(d_{t+1}+q_{t+1}\right) \theta_{t+1}^{U} .
\end{aligned}
$$

The young can save in two assets. $k_{t+1}^{i}$ denotes the supply of capital and $\theta_{t+1}^{i}$ the number of shares bought by consumer of type $i . q_{t}$ is the price of a share in period $t$, and $d_{t+1}$ denotes the dividend per share paid in period $t+1 . w_{t}$ is the wage rate and $b_{t}$ is the exogenously given unemployment insurance compensation. $R_{t+1}$ is the interest factor (and the gross return on capital) between periods $\mathrm{t}$ and $\mathrm{t}+1$. Because there is no uncertainty, there is an obvious arbitrage condition here, which says that the return on investing in capital should be equal to investing in the 
shares of the firms, i.e. $R_{t+1}=\left(d_{t+1}+q_{t+1}\right) / q_{t}$. This means that the lifetime budget constraint is $c_{1}^{t, i}+c_{2}^{t, i} / R_{t+1}=I_{t}^{i}$, where $I_{t}^{i}$ denotes the income of the type $i$ workerconsumer.

We can define total savings as $s_{t}^{i}=k_{t+1}^{i}+q_{t} \theta_{t+1}^{i}$. Given the utility function the saving can be solved to get $s_{t}^{i}=(1-\lambda) I_{t}^{i}$, where $\lambda$ is constant. This means that total savings do not depend on the interest factor, because with Cobb-Douglas utility function the substitution and income effect cancel each other out. We can thus write the indirect utility functions of both types as

$$
\begin{aligned}
& V^{E}(w, R)=\lambda^{\lambda}(1-\lambda)^{1-\lambda} R^{1-\lambda} w=\hat{\lambda} R^{1-\lambda} w \\
& V^{U}(w, R)=\lambda^{\lambda}(1-\lambda)^{1-\lambda} R^{1-\lambda} b=\hat{\lambda} R^{1-\lambda} b,
\end{aligned}
$$

where $\hat{\lambda}=\lambda^{\lambda}(1-\lambda)^{1-\lambda}$. Thus the utility depends positively both on wage income and the rate of return on savings.

The firms are assumed to have the following production function: $F(K, L)^{\mu}=\left(K^{\alpha} n^{1-\alpha}\right)^{\mu}$, with $0<\alpha<1$ and $0<\mu<1$. The restriction on the parameter $\mu$ can be given three different justifications.

We can assume that (i) the production function has decreasing returns-toscale so that $\mu<1$. In this case we also have decreasing returns to scale in terms of capital and labour. (ii) Our decreasing returns to scale specification can be justified also in a realistic way by assuming that (a) the production technology has a property of constant returns to scale in terms of capital and labour so that $\alpha+\beta=1$, but (b) product markets are imperfectly competitive. Assuming e.g. an iso-elastic demand function $D(p)=p^{-\varepsilon}$ ( $p$ is the product price), we can write the firm's gross revenue function as $p F=F^{1-(1 / \varepsilon)}$, where the price elasticity of product demand is higher than one, but less than infinity i.e. $\mu=1-(1 / \varepsilon)<1$. This monopolistic competition assumption (see e.g. Dixit and Stiglitz 1977) also provides a justification for our decreasing returns to scale assumption in production technology. (iii) Finally, this can also be justified by assuming that there is a three factor technology with constant returns to scale, i.e. $F(K, n, M)=K^{\alpha} n^{\beta} M^{1-(\alpha+\beta)}$, when input $M$ is fixed.

The firms rent capital from consumers and hire labour. Their profit will be 


$$
\Pi_{t}=F\left(K_{t}, L_{t}\right)^{\mu}-w_{t} n_{t}-r_{t} K_{t} .
$$

We will consider the case of what Devereux and Lockwood (1991) call a non-binding solution. This means that firms have committed to a level of capital stock before they negotiate about the wage (see also de la Croix and Licandro (1995)). In a recent study Hellwig (2004) has compared a number of key properties associated with two alternative timing structures between negotiated wage setting and investment decisions within the framework of an intertemporal general equilibrium model. He suggests that although the long-term labour demand with endogenous investment is more elastic than the short-term demand, it does not necessarily lead to a less aggressive wage policy. The wage-employment trade-off in his model depends on whether the elasticity of substitution in production is lower than or higher than the inverse of the elasticity of marginal utility in consumption. Our present analysis does not address these hold-up problems. They might be particularly important, if firms can adjust their investment decisions in the short run.

The first-order condition for employment is (dropping the time subscripts for convenience) with a given level of capital stock

$$
(1-\alpha) \mu K^{\alpha \mu} n^{(1-\alpha) \mu-1}=w .
$$

Solving the labor demand we get

$$
n=(1-\alpha)^{\eta} \mu^{\eta} K^{\alpha \mu \eta} w^{-\eta}=\left[((\eta-1) / \eta)^{\eta}\right] K^{\alpha \mu \eta} w^{-\eta},
$$

where $\eta=-n_{w} w / n=1 /[1-\mu(1-\alpha)]$, which is greater than unity because $0<\mu, \alpha<1$. We denote by $(\eta-1) / \eta=B<1$. Labour demand depends negatively on wage and positively on capital stock, since capital and labour are complements in production, i.e. $F_{n K}>0$.

The representative firm and the trade union negotiate about the wage given that the firms are on their labour demand curve. Instead of efficient bargaining we use the RTM approach. The negotiated wage rate can then be solved from the following Nash bargaining problem

$$
\underbrace{\operatorname{Max}}_{w_{t}} \Omega_{t}=\left(U_{t}-\bar{U}_{t}\right)^{\beta}\left(\Pi_{t}-\bar{\Pi}_{t}\right)^{1-\beta} \text { s.t. } n=B^{\eta} K^{\alpha \mu \eta} w^{-\eta}
$$


where $U_{t}\left(\bar{U}_{t}\right)$ denotes the utility (fallback utility) of the trade union, $\bar{\Pi}_{t}$ is the fallback profit of the firm and $\beta$ denotes the relative bargaining power of trade union. ${ }^{1}$ Trade union cares about the employed and unemployed. Thus we assume that $U_{t}=n_{t} V_{t}^{E}+\left(1-n_{t}\right) V_{t}^{U}$. Since an unemployed person gets an unemployment insurance compensation we assume that $\bar{U}_{t}=V_{t}^{U}$. Given the fact that firms have committed to the level of capital stock before wage negotiations, they have to pay the rentals even in the case of no agreement. This means that $\bar{\Pi}_{t}=-r_{t} K_{t}$.

Incorporating the fallback utility and profit into $(\mathrm{PN})$ we can now rewrite the RTM Nash bargaining problem as

$\left(\mathrm{PN}^{\prime}\right) \quad \underbrace{\operatorname{Max}}_{w_{t}} \Omega_{t}=\left[\hat{\lambda} R_{t+1}\left(w_{t}-b_{t}\right) n_{t}\right]^{\beta}\left[F\left(K_{t}, n_{t}\right)^{\mu}-w_{t} n_{t}\right]^{1-\beta}$

$$
\text { s.t. } n=B^{\eta} K^{\alpha \mu \eta} w^{-\eta} \text {. }
$$

The first-order condition reduces to

$$
\frac{\beta\left[w_{t}(1-\eta)+b_{t} \eta\right]}{w_{t}-b_{t}}=\frac{(1-\beta) w_{t} n_{t}}{F\left(K_{t}, n_{t}\right)-w_{t} n_{t}} .
$$

Given the production function, equation (8) can be expressed in a standard way as

$$
w_{t}^{N}=\frac{[\beta+\eta-1]}{[\eta-1]} b_{t} .
$$

The negotiated wage depends positively on the level of unemployment insurance compensation and trade union's relative bargaining power, while negatively on the wage elasticity of labour demand, which becomes higher with more intensified product market competition. It is important to keep in mind that in the case of Cobb-Douglas production function the negotiated wage does not depend on the level of capital stock, since the wage elasticity of labour demand is constant, i.e. it only depends on the parameters $\mu=1-\frac{1}{\varepsilon}$ and $\alpha$.

1 The Nash maximand (PN' below), i.e. the weighted product of the net gains of the bargainers, can be justified both via the axiomatic approach by Nash (1950) and via the strategic approach by Rubinstein (1982). These approaches are of course very different, but interestingly, Nash's axiomatic solution can also be obtained as a limit solution to a non-cooperative game in which the time interval between alternative offers approaches zero (see Binmore et. al, 1986 for a proof of this assertion). 
The negotiated wage means that the share of output going to the employed workers (i.e. $w_{t}^{N} n_{t}$ ) is

$$
w^{N} n=B^{\eta} K^{\alpha \mu \eta}\left[\frac{\beta+\eta-1}{\eta-1}\right]^{1-\eta} b^{1-\eta} .
$$

The share of output going to the owners $\left(F^{\mu}-w n\right)$ can be expressed as follows

$$
\begin{aligned}
& F(K, n)^{\mu}-w^{N} n=B^{\eta-1} K^{\alpha \mu \eta}\left[\frac{\beta+\eta-1}{\eta-1}\right]^{1-\eta} b^{1-\eta} \\
& -B^{\eta} K^{\alpha \mu \eta}\left[\frac{\beta+\eta-1}{\eta-1}\right]^{1-\eta} b^{1-\eta}=B^{\eta-1} K^{\alpha \mu \eta}\left[\frac{\beta+\eta-1}{\eta-1}\right]^{1-\eta} b^{1-\eta}[1-B]
\end{aligned}
$$

In what follows we denote the mark-up between the negotiated wage and unemployment insurance compensation by $(\beta+\eta-1) /(\eta-1) \equiv A$. Thus we can rewrite equation (11) as follows

$$
F(K, n)^{\mu}-w^{N} n=B^{\eta-1} K^{\alpha \mu \eta} A^{1-\eta} b^{1-\eta}[1-B] .
$$

We can now write dividends ( $\left.D i v=F^{\mu}-w n-r K\right)$ as

$$
\text { Div }=B^{\eta-1} K^{\alpha \mu \eta} A^{1-\eta} b^{1-\eta}[1-B]-r K .
$$

We first note that $\alpha \mu \eta=\alpha \mu /(1-\mu(1-\alpha))<1, \quad$ and $B^{\eta-1} A^{1-\eta} b^{1-\eta}[1-B] \equiv H>0$. The partial derivatives of $H$ are: $H_{A}<0$ and $H_{b}<0$. We also note that $H_{B} \equiv A^{1-\eta} b^{1-\eta}[\eta(1-B)-1]$ so that $H_{B}=0$, since $\eta(1-B)=1$. The signs of derivatives are intuitive. A higher mark-up and higher unemployment insurance compensation will increase the wage demands, and thus have a negative effect on dividends.

We note that dividend is a strictly concave function of the capital stock, and fulfils the conditions $\lim _{K \rightarrow 0} \frac{\partial D i v}{\partial K}=\infty$ and $\lim _{K \rightarrow \infty} \frac{\partial D i v}{\partial K}=-r$. There is then an interior maximizing solution given that $H>0$. The first-order condition for a maximum capital stock will then be

$$
\alpha \mu \eta K^{\alpha \mu \eta-1} H=r,
$$

where we can solve for the optimal capital stock and also use it to compute the dividend as a function of the capital stock as 


$$
\operatorname{Div}=K^{\frac{\alpha \mu}{1-\mu(1-\alpha)}} H\left[\frac{1-\mu}{1-\mu(1-\alpha)}\right]=K^{\alpha \mu \eta} H(1-\mu) \eta .
$$

In the next section we explore stability and dynamics under flexible RTM wage negotiations.

\section{Steady States and Dynamical Equilibria under Flexible Wage Negotiation}

We can now characterize the equilibrium of this economy. Saving must be allocated to the capital stock and the shares of the firm. The second equilibrium condition is the arbitrage condition for the returns from investing in the capital stock and the shares. The total capital stock $\left(K_{t+1}\right)$ must be equal to the amount saved to capital by the employed and unemployed workers (i.e. $\left.n_{t} k_{t+1}^{E}+\left(1-n_{t}\right) k_{t+1}^{U}\right)$. We normalize the aggregate number of shares to be unity, i.e. that $n_{t} \theta_{t+1}^{E}+\left(1-n_{t}\right) \theta_{t+1}^{U}=1$. Given this normalization and the utility function (i.e. the saving behavior) we get the following capital market equilibrium condition

$$
K_{t+1}=(1-\lambda)\left[n_{t}\left(w_{t}-b_{t}\right)+b_{t}\right]-q_{t} .
$$

The arbitrage condition,

$$
q_{t+1}=\left(1+r_{t+1}\right) q_{t}-d_{t+1}
$$

is the other equilibrium condition.

Given the negotiated wage (9), the first order condition for a maximum capital stock (15) and the dividend as a function of the capital stock (16) we get the following dynamical system for the capital stock and the share price

$$
\begin{aligned}
& \left.K_{t+1}=(1-\lambda) \mid K_{t}^{\alpha \mu \eta}(A b)^{-\eta} B^{\eta} b(A-1)+b\right]-q_{t} \\
& q_{t+1}=\left[1+\alpha \mu \eta K_{t+1}^{\alpha \mu \eta-1} H\right] q_{t}-K_{t+1}^{\alpha \mu \eta} H(1-\mu) \eta .
\end{aligned}
$$

In the steady state $\left(\Delta K_{t}=0\right.$ and $\left.\Delta q_{t}=0\right)$ we have

$$
\begin{aligned}
& q=(1-\lambda) b+(1-\lambda)\left[K^{\alpha \mu \eta}(A b)^{-\eta} B^{\eta} b(A-1)\right]-K \equiv G(K) \\
& q=\frac{K^{\alpha \mu \eta} H(1-\mu) \eta}{\alpha \mu \eta K^{\alpha \mu \eta-1} H}=\frac{1-\mu}{\alpha \mu} K .
\end{aligned}
$$

The first equation describing the capital market equilibrium condition in steady state is nonlinear, while the second one, describing the arbitrage condition, is linear. We note from (21) that $G(0)=(1-\lambda) b>0$ and 
$G^{\prime}(K)=(1-\lambda)(\alpha \mu \eta)(A b)^{-\eta} B^{\eta} b(A-1) K^{\alpha \mu \eta-1}-1$. We can see that $\lim _{K \rightarrow 0} G^{\prime}(K)=\infty$ and $\lim _{K \rightarrow \infty} G^{\prime}(K)=-1$. One can see that the slope of (22) decreases, when the elasticity of output with respect to capital stock $(\alpha \mu)$ increases. These properties imply that we can draw the following diagram, which shows that the steady state $(K *)$ is unique.

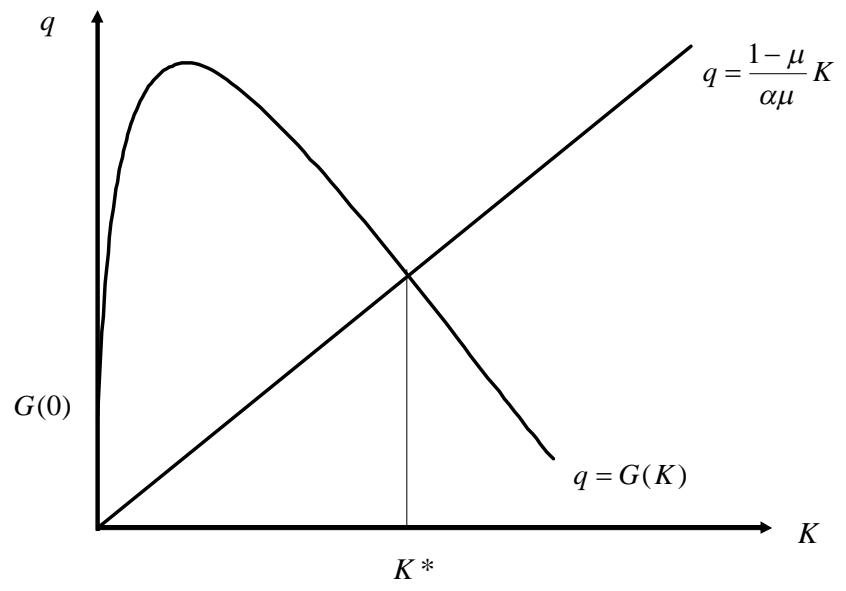

Figure 1. Steady state.

We collect the previous findings in the following Proposition.

Proposition 1: With Cobb-Douglas utility and production functions the steady state of the OG economy described by equations (21) and (22) is unique, when wages are decided by the RTM bargaining before the capital stock.

What happens to the steady state capital stock, when trade union's bargaining power is higher? Bargaining power affects only the first steady state equation (21). We present the result in the next Proposition.

Proposition 2: With Cobb-Douglas utility and production functions, and with RTM bargaining before the capital stock decision the steady state capital stock is higher the bigger is the trade union's bargaining power. 
Proof: The bargaining power, $\beta$, affects the curve (21) through the term $A=(\beta+\eta-1) /(\eta-1)$. The total effect can be obtained by considering the effect of $\beta$ on $\quad A^{1-\eta}-A^{-\eta} \quad$ (see equation (21)). Differentiating we get $\frac{\partial}{\partial \beta}\left(A^{1-\eta}-A^{-\eta}\right)=A_{\beta}(1-\beta) A^{-\eta-1}$. This is positive, since $A_{\beta}=1 /(\eta-1)>0$. This means that the curve (21) shifts up, when the bargaining power is increased, and thus the steady state capital stock increases. Q.E.D.

Proposition 2 follows from the fact that the improved bargaining power will induce workers to save more, ceteris paribus, which in turn boosts the capital stock.

Next we study the dynamics of the model by considering paths for which $K_{t+1} \geq K_{t}$ and $q_{t+1} \geq q_{t}$. It follows from (19) that

$$
\begin{aligned}
& \left.K_{t+1} \geq K_{t} \Leftrightarrow(1-\lambda) \mid K_{t}^{\alpha \mu \eta}(A b)^{-\eta} B^{\eta} b(A-1)+b\right]-q_{t} \geq K_{t} . \\
& \Rightarrow q_{t} \leq(1-\lambda)\left[K_{t}^{\alpha \mu \eta}(A b)^{-\eta} B^{\eta} b(A-1)+b\right]-K_{t} \equiv M\left(K_{t}\right) .
\end{aligned}
$$

We note that capital stock is growing below the curve $q_{t}=M\left(K_{t}\right)$.

It follows from (20) for the dynamics of the arbitrage equation that

$$
\begin{aligned}
& q_{t+1} \geq q_{t} \Leftrightarrow\left[1+\alpha \mu \eta K_{t+1}^{\alpha \mu \eta-1} H\right] q_{t}-K_{t+1}^{\alpha \mu \eta} H(1-\mu) \eta \geq q_{t} \\
& \Rightarrow \quad q_{t} \geq \frac{K_{t+1}^{\alpha \mu \eta} H(1-\mu) \eta}{\alpha \mu \eta K_{t+1}^{\alpha \mu \eta-1} H}=\frac{1-\mu}{\alpha \mu} K_{t+1},
\end{aligned}
$$

because $\eta(1-\mu+\alpha \mu)=1$. We have thus obtained that $q_{t+1} \geq q_{t}$ implies that $q_{t} \geq((1-\mu) / \alpha \mu) K_{t+1}$. To go on to analyse the paths, where $q_{t+1} \geq q_{t}$, we substitute the expression for $K_{t+1}$ from equation (19) and obtain

$$
q_{t} \geq \frac{1-\mu}{\alpha \mu}\left\{(1-\lambda)\left[K_{t}^{\alpha \mu \eta}(A b)^{-\eta} B^{\eta} b(A-1)+b\right]-q_{t}\right\},
$$

which can be rewritten as

$$
q_{t} \geq \alpha \mu \eta(1-\lambda)\left[K_{t}^{\alpha \mu \eta}(A b)^{-\eta} B^{\eta} b(A-1)+b\right] \equiv Q\left(K_{t}\right) .
$$

The share price is increasing above the curve $q_{t}=Q\left(K_{t}\right)$. By differentiating (23) and (26) with respect to $K$ we obtain

$$
\begin{aligned}
& M^{\prime}(K)=(1-\lambda)(\alpha \mu \eta)(A b)^{-\eta} B^{\eta} b(A-1) K^{\alpha \mu \eta-1}-1 \\
& Q^{\prime}(K)=(\alpha \mu \eta)^{2}(1-\lambda)(A b)^{-\eta} B^{\eta} b(A-1) K^{\alpha \mu \eta-1}
\end{aligned}
$$


Furthermore, we note that $M(0)=(1-\lambda) b>Q(0)=\alpha \mu \eta(1-\lambda) b, \quad \lim _{K \rightarrow 0} M^{\prime}(K)=\infty$ and $\lim _{K \rightarrow 0} Q^{\prime}(K)=\infty$. In addition we have that $\lim _{K \rightarrow \infty} M^{\prime}(K)=-1$ and $\lim _{K \rightarrow \infty} Q^{\prime}(K)=0$. We have already proved that the steady state is unique. Thus we can depict the qualitative features of our model in Figure 2. The Figure indicates that the steady state is a saddle.

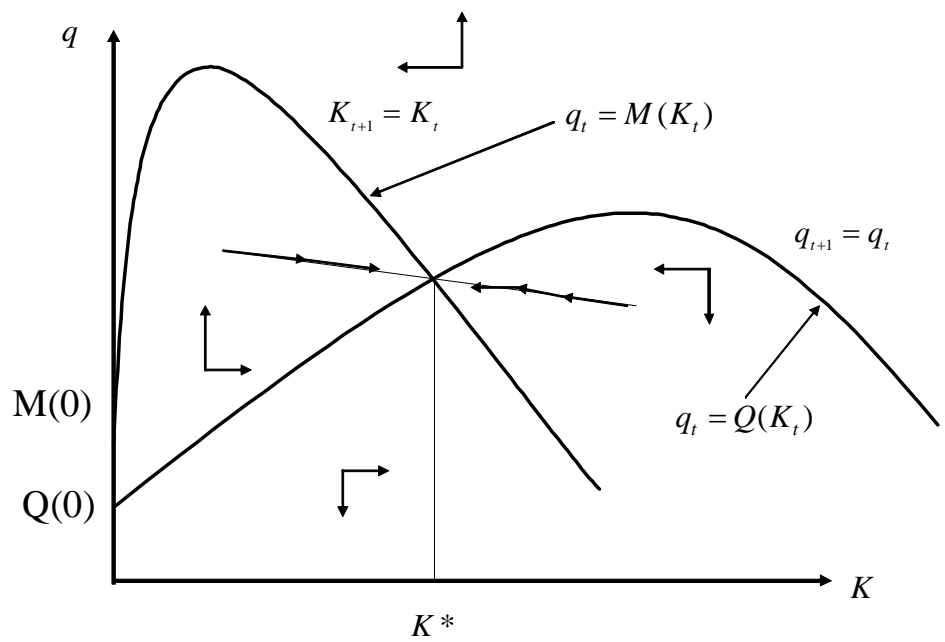

Figure 2. Dynamics.

To study formally the stability properties of dynamical equilibrium, we rewrite equation (19) as follows

$$
K_{t+1}=(1-\lambda)\left[K_{t}^{\alpha \mu \eta}(A b)^{-\eta} B^{\eta} b(A-1)+b\right]-q_{t} \equiv Z\left(K_{t}, q_{t}\right)
$$

Substituting the RHS of (29) for $K_{t+1}$ in (20) gives an implicit equation for $q_{t+1}$,

$$
q_{t+1}=P\left(K_{t}, q_{t}\right)
$$

The planar system describing the dynamics of the capital stock and the share price consists now of equations (29) and (30). The Jacobian matrix of the partial derivatives of the system (29)-(30) can be written as

(31) $J=\left[\begin{array}{ll}Z_{K} & Z_{q} \\ P_{K} & P_{q}\end{array}\right]$,

where

$$
\begin{aligned}
& Z_{K}=(1-\lambda)\left[(\alpha \mu \eta) K^{\alpha \mu \eta-1}(A b)^{-\eta} B^{\eta} b(A-1)\right] \\
& Z_{q}=-1
\end{aligned}
$$




$$
\begin{aligned}
& P_{q}=1+\alpha \mu \eta K^{\alpha \mu \eta-1} H-\frac{\partial q_{t+1}}{\partial K_{t+1}} \\
& P_{K}=-(A b)^{-\eta} B^{\eta} b(A-1) \eta^{2}(1-\mu)(1-\lambda) \alpha \mu H K^{2(\alpha \mu \eta-1)}<0 \quad \text { (See Appendix } 1 \text { for }
\end{aligned}
$$
details).

We prove the following

Proposition3: The steady state equilibrium is a saddle point.

Proof. See Appendix 2.

\section{Conclusions}

We have explored the stability and dynamics in an overlapping generations economy with wage bargaining. Under right-to manage bargaining, where employment is not negotiated but decided by firms, we have assumed that wage is negotiated given the capital stock and that wage bargaining process takes place between the young workers and the old capitalists. We have provided the following results.

With Cobb-Douglas utility and production functions the economy's steady state is unique and the steady state capital stock depends positively on the trade union's bargaining power. This is because the higher bargaining power of the trade union will induce workers to save more, which boosts the capital stock. Finally, we study the dynamics of the model and show that in this OLG framework under imperfectly competitive labour markets the steady state equilibrium is a saddle point.

An interesting further research topic would be to analyse these issues in the open economy framework (for one such an OG specification, see Bertocchi 2003) and in the presence of outsourcing of economic activities under imperfectly competitive labour markets (see e.g. Skaksen and Sorensen 2001). 


\section{Appendix 1: Derivation of the partials of the Jacobian matrix.}

We rewrite equation (20) as follows

(A1) $\quad q_{t+1}=q_{t}+\alpha \mu \eta K_{t+1}^{\alpha \mu \eta-1} H q_{t}-(1-\mu) \eta K_{t+1}^{\alpha \mu \eta} H$.

We first compute $P_{q}$ and evaluate it at the steady state to get

(A2) $P_{q}=1+\alpha \mu \eta K^{\alpha \mu \eta-1} H-\frac{\partial q_{t+1}}{\partial K_{t+1}}$,

since from the analysis in the text we know that $\partial K_{t+1} / \partial q_{t}=-1$. Computing from (A1) we get

$$
\begin{aligned}
& \text { A3) } \frac{\partial q_{t+1}}{\partial K_{t+1}}=(\alpha \mu \eta)(\alpha \mu \eta-1) K^{\alpha \mu \eta-2} H q-\alpha \mu(1-\mu) \eta^{2} K^{\alpha \mu \eta-1} H \\
& =\alpha \mu \eta K^{\alpha \mu \eta-2} H[(\alpha \mu \eta-1) q-(1-\mu) \eta K]=-(1-\mu) \eta K^{\alpha \mu \eta-1} H<0
\end{aligned}
$$

This means that

(A4) $P_{q}=1+K^{\alpha \mu \eta-1} H$,

Next we compute $P_{K}$. From (A1) we want to compute $\frac{\partial q_{t+1}}{\partial K_{t+1}} \frac{\partial K_{t+1}}{\partial K_{t}}\left(=P_{K}\right)$. We have $\partial q_{t+1} / \partial K_{t+1}$ from (A3), and get from (29)

(A5) $\frac{\partial K_{t+1}}{\partial K_{t}}=(1-\lambda)(\alpha \mu \eta)(A b)^{-\eta} B^{\eta} b(A-1) K^{\alpha \mu \eta-1}$.

Thus we get

(A6) $\quad P_{K}=-(A b)^{-\eta} B^{\eta} b(A-1) \eta^{2}(1-\mu)(1-\lambda) \alpha \mu H K^{2(\alpha \mu \eta-1)}<0$.

We can also express this as $P_{K}=-(1-\mu) Z_{K} \eta H K^{\alpha \mu \eta-1}$.

\section{Appendix 2: Proof of Proposition 3.}

We analyze the stability of the system (19) and (20), which characterizes the dynamics of the capital stock and the share price. The characteristic polynomial associated with the system (28) and (29) expressed in terms of D and T is

(A7) $\quad p(\lambda)=\lambda^{2}-T \lambda+D=0$

It is known from the stability theory of difference equations (see e.g. Azariadis, 1993, pp. 63-67, and de la Croix and Michel, 2002, pp. 321-322) that for a saddle point to exist the roots of $p(\lambda)=0$ need to be on both sides of (minus and plus) unity. Thus for a saddle we need that $\mathrm{D}-\mathrm{T}+1<0$ and $\mathrm{D}+\mathrm{T}+1>0$ or $\mathrm{D}-\mathrm{T}+1>0$ and $\mathrm{D}+\mathrm{T}+1<0$.

The planar system describing the dynamics of the capital stock and the share price consists now of equations (29) and (30). The Jacobian matrix of the partial derivatives of the system can be written as

(A8) $J=\left[\begin{array}{ll}Z_{K} & Z_{q} \\ P_{K} & P_{q}\end{array}\right]$,

where

$$
\begin{aligned}
& Z_{K}=(1-\lambda)\left[(\alpha \mu \eta) K^{\alpha \mu \eta-1}(A b)^{-\eta} B^{\eta} b(A-1)\right]>0 \\
& Z_{q}=-1
\end{aligned}
$$




$$
\begin{aligned}
P_{K} & =-Z_{K} \eta H K^{\alpha \mu \eta-1} \\
P_{q} & =1+K^{\alpha \mu \eta-1} H .
\end{aligned}
$$

Computing the trace $\left(T=Z_{K}+P_{q}\right)$ and determinant $\left(D=Z_{K} P_{q}+P_{K}\right)$ we obtain

(A9) $\quad T=(1-\lambda)\left[(\alpha \mu \eta) K^{\alpha \mu \eta-1}(A b)^{-\eta} B^{\eta} b(A-1)\right\rfloor+1+K^{\alpha \mu \eta-1} H>1$

(A10) $D=Z_{K} P_{q}-(1-\mu) Z_{K} \eta H K^{\alpha \mu \eta-1}=Z_{K}\left[1+K^{\alpha \mu \eta-1} H-\eta(1-\mu) K^{\alpha \mu \eta-1} H\right]=$ $Z_{K}\left[1+K^{\alpha \mu \eta-1} H(1-\eta(1-\mu)]=Z_{K}\left[1+K^{\alpha \mu \eta-1} H(\alpha \mu \eta)\right]>0\right.$.

Now we conclude that $D+T+1>0$. Next we compute $D-T+1$ to get

(A11) $D-T+1=-K^{\alpha \mu \eta-1} H\left[1-\alpha \mu \eta Z_{K}\right]$.

Rewriting we get

(A12) $\quad D-T+1=-K^{\alpha \mu \eta-1} H\left[1-(1-\lambda)(\alpha \mu \eta)^{2} K^{\alpha \mu \eta-1}(A b)^{-\eta} B^{\eta} b(A-1)\right]$.

We next develop the term $(1-\lambda)(\alpha \mu \eta)^{2} K^{\alpha \mu \eta-1}(A b)^{-\eta} B^{\eta} b(A-1)$ from (A12), and denote it by $Y$. Using the steady state relations (21) and (22) we can express $Y$ as follows

$$
\begin{aligned}
& Y(\bullet)=\frac{(1-\lambda)(\alpha \mu \eta)^{2} K^{\alpha \mu \eta}(A b)^{-\eta} B^{\eta} b(A-1)}{K}= \\
& \frac{(\alpha \mu \eta)[K-(1-\lambda) \alpha \mu \eta b]}{K}=(\alpha \mu \eta)\left[1-(1-\lambda) \alpha \mu \eta \frac{b}{K}\right] .
\end{aligned}
$$

Since the original term is positive, and the fact that $\alpha \mu \eta<1$, this must be less than unity. This means that $D-T+1<0$ so that we have a saddle. Q.E.D.

\section{References:}

Anderson, S.P. and M.B. Devereux (1988): Trade Unions and the Choice of Capital Stock, Scandinavian Journal of Economics 90(1), 27-44.

Anderson, S.P. and M.B. Devereux (1991): The Trade-off between Precommitment and Flexibility in Trade Union Wage Setting, Oxford Economic Papers 43, 549-569.

Azariadis, C. (1993): Intertemporal Macroeconomics, Blackwell, Oxford.

Bertocchi, G. (2003): Labor Market Institutions, International Capital Mobility, and the Persistence of Underdevelopment, Review of Economic Dynamics 6, 637-650.

Binmore, K., Rubinstein, A. and A. Wolinsky (1986): The Nash Solution in Economic Modeling, Rand Journal of Economics 17(2), 176-188.

Cahuc, P. and A. Zylberberg (2004): Labor Economics, MIT Press.

de la Croix, D. and O. Licandro (1995): Underemployment, Irreversibilities and Growth under Trade Unionism, Scandinavian Journal of Economics 97,385399.

de la Croix, D. and P. Michel (2002): A Theory of Economic Growth: Dynamics and Policy in Overlapping Generations, Cambridge University Press.

Devereux, M.B. and B. Lockwood (1991): Trade Unions, Non-binding Wage Agreements, and Capital Accumulation, European Economic Review 35,1411-1426. 
Diamond, P. (1965): National Debt in a Neoclassical Growth Model, American Economic Review 55, 1026-1050.

Dixit, A.K. and J.E. Stiglitz (1977): Monopolistic Competition and Optimum Product Diversity, American Economic Review 67, 297-308.

Dos Santos Ferreira, R. and T. Lloyd-Braga (2002): Can Market Power Sustain Endogenous Growth in Overlapping Generations Economies? Economic Theory 20, 199-205.

Grout, P.A. (1984): Investment and Wages in the Absence of Binding Contracts: A Nash Bargaining Approach, Econometrica 52, 449-460.

Hellwig, M. (2004): The Relation between Real Wage Rates and Employment: An Intertemporal General Equilibrium Analysis. German Economic Review 5, 263-295.

Nash, J. (1950): The Bargaining Problem, Econometrica 18, 155-162.

Rubinstein, A. (1982): Perfect Equilibrium in a Bargaining Model, Econometrica 50, 97-109.

Skaksen, M.Y. and J.R. Sorensen (2001): Should Trade Unions Appreciate Foreign Direct Investment?, Journal of International Economics, 55, 379390.

van der Ploeg, R. (1987): Trade Unions, Investment and Unemployment: A Noncooperative Approach, European Economic Review 31, 1469-1492. 